\title{
Errors in short-term memory for good and poor readers
}

\author{
SUSAN BRADY \\ University of Rhóde Island, Kingston, Rhode Island \\ and Haskins Laboratories, New Haven, Connecticut \\ VIRGINIA MANN \\ University of California, Irvine, California \\ and Haskins Laboratories, New Haven, Connecticut \\ and \\ RICHARD SCHMIDT \\ University of Connecticut, Storrs, Connecticut \\ and Haskins Laboratories, New Haven, Connecticut
}

\begin{abstract}
This study examined the role of phonetic factors in the performance of good and poor beginning readers on a verbal short-term memory task. Good and poor readers in the second and third grades repeated four-item lists of consonant-vowel syllables in which each consonant shared zero, one, or two features with other consonants in the string. As in previous studies, the poor readers performed less accurately than the good readers. However, the nature of their errors was the same: Both groups tended to transpose initial consonants as a function of their phonetic similarity and adjacency. These findings suggest that poor readers are able to employ a phonetic coding strategy in short-term memory, as do good readers, but less skillfully.
\end{abstract}

Children who have difficulty learning to read have consistently been found to perform less well than good readers on a wide variety of short-term memory (STM) tasks (Bauer, 1977; Brady, Shankweiler, \& Mann, 1983; Hogaboam \& Perfetti, 1978; Jorm, 1983; Katz, Healy, \& Shankweiler, 1983; Liberman, Shankweiler, Liberman, Fowler, \& Fischer, 1977; Mann, Liberman, \& Shankweiler, 1980; Shankweiler, Liberman, Mark, Fowler, \& Fischer, 1979; Torgesen, 1982). For example, they are distinguished from good readers by their tendency to make more errors on serial recall tasks involving such diverse materials as auditorily presented letter names (Shankweiler et al., 1979), words (Brady et al., 1983; Mann et al., 1980), and sentences (Mann et al., 1980; Mann, Shankweiler, \& Smith, 1984). They also are deficient in their memory for printed words (Mark, Shankweiler, Liberman, \& Fowler, 1977) and letter strings (Katz et al., 1983; Shankweiler et al., 1979). Even pictures of nameable objects are remembered less well by poor readers, although recall of nonsense "doodle" drawings does not differentiate reading groups (Katz, Shankweiler, \& Liberman, 1981). This final observation is important because it reveals that not all types of material enable us to distin-

We wish to thank Isabelle Liberman and Donald Shankweiler for insightful criticisms of earlier versions of the paper. The research and the preparation of the manuscript were supported in part by a grant to Haskins Laboratories from the National Institute of Child Health and Human Development (HD-01994). Address correspondence to Susan Brady, Haskins Laboratories, 270 Crown St., New Haven, CT 06511. guish good and poor readers (Liberman, Mann, Shankweiler, \& Werfelman, 1982; Vellutino, Pruzek, Steger, $\&$ Meshoulam, 1973). Thus it would not be appropriate to conclude that poor readers suffer from some general memory impairment. Rather, they appear deficient only in the ability to remember linguistic material, whether presented by ear or by eye (Liberman et al., 1982; Shankweiler et al., 1979). That is, the commonality among the many materials that distinguish the STM performance of good and poor readers is that retaining these materials in working memory involves reliance on phonetic coding. Thus we are led to seek an explanation of the poor readers' STM impairment in the realm of phonetic coding itself, rather than in the process of translating printed information into a phonetic code.

To develop our line of reasoning more completely, we refer to three lines of evidence suggesting that the deficits poor readers display on STM tasks are related to less efficient phonetic coding processes. First, as mentioned above, the contrast between reading groups in performance on STM tasks seems to be restricted to procedures that employ "phonetically recodable" stimuli. When visual stimuli are selected that do not lend themselves to phonetic coding, the performances of good and poor readers are the same. For example, for stimuli such as photographs of strangers, nonsense doodle drawings, or symbols from an unfamiliar writing system, recall by good and poor readers is comparable (Katz et al., 1981; Liberman et al., 1982; Vellutino et al., 1973). Similarly, in memory for auditory stimuli that are not readily recoded 
phonetically (e.g., tones), poor readers perform equally well on STM tasks (Holmes \& McKeever, 1979). The difference between reading groups for recall of phonetically recodable stimuli (e.g., letters, words, and nameable objects) and the lack of difference in performance for stimuli that are "phonetically unrecodable" highlight the poor readers' difficulty with the use of a phonetic code.

A second line of evidence finds that manipulations of certain phonetic properties of stimuli in an STM task generally have less effect on the performance of young poor readers than on that of good readers (Brady et al., 1983; Liberman et al., 1977; Mann et al., 1980; Mark et al., 1977; Olson, Davidson, Kliegl, \& Davies, 1984; Shankweiler et al., 1979). With stimuli in which there is a low density of phonetic confusability (i.e., nonrhyming items), good readers' recall is superior; however, if a high density of confusability is present, the performance of good readers is impaired much more than that of poor readers. It has been supposed that for good readers the effect of manipulating the density of phonetically confusable items, also found for adults (Baddeley, 1966; Conrad, 1972), results from the fact that they rely on phonetic coding for the maintenance of information in STM. Stimuli that introduce confusion among the phonetic representations in STM penalize use of phonetic coding and therefore tend to have a greater effect on the performance of the more skilled readers. The fact that phonetic confusability has less of an effect on the performance of the poor readers suggests that they either fail to employ a phonetic code or for some reason do so less well.

Third, and of primary concern to us here, is evidence that poor readers may make use of a phonetic code, and not some other coding strategy, but may do so less accurately or efficiently than do good readers (Katz, 1986). Earlier, Conrad (1971) reported that children 6 years of age or older produce the same pattern of results on STM tasks as do adults, namely better recall for nonrhyming sets of pictures than for rhyming sets. In contrast, children younger than 6 years of age did not show a difference in recall for the nonrhyming set. This study raised the question of whether young children might initially use some other, nonphonetic, coding strategy in short-term memory. However, more recent research with even younger children ( 4 years) has found the adult pattern, suggesting phonetic coding on the part of children as young as 4 years of age (Alegria \& Pignot, 1979). That is to say, in the Alegria and Pignot experiments, 4-year-old children recalled nonrhyming items better than rhyming items, leading the authors to conclude that by 4 years of age children are already using a phonetic code to store and organize information in short-term memory. Thus, at the present, questions can be raised as to whether there are developmental changes in the type of code employed in short-term memory. By extension, questions can also be raised as to whether poor readers are using a nonphonetic strategy, or the same phonetic strategy that the better readers employ.

Several studies have probed the coding strategies of poor readers. Using a paradigm that tested recall for time periods longer than the assumed limits of STM, Byrne and Shea (1979) obtained evidence that children who were poor readers were able to use a phonetic code (albeit poorly) when forced to do so by the use of pseudoword stimuli, but otherwise tended to favor a semantic code (although at least one study failed to replicate this finding [Winbury, 1984]). However, when some of us examined the errors that good and poor readers made on a standard word string repetition task, we found no indication that either group of children was using a semantic strategy (Brady et al., 1983). Instead, the errors of the poor readers, like those of good readers, indicated that the stimuli were being processed phonetically. Out of the 437 intrusion errors (items that were not in the original list) made by both reading groups, only one appeared to have been a possible semantic error (station for train); the vast majority of the remaining errors indicated that children recombined phonetic units that had been present in either the string being recalled or the preceding string. What was noteworthy about the errors made was that, rather than being semantically based errors, they appeared to reflect a phonetic coding strategy for both reading groups. However, consistent with the view that poor readers encounter some difficulty with phonetic coding, the incidence of recombinations (transpositions) of the phonetic information was significantly more frequent for the poor readers; hence, their performance was poor on the repetition task.

In sum, present evidence is consistent with a hypothesis that poor readers are somehow deficient in creating and/or maintaining a phonetic code and that this compromises their performance on verbal short-term memory tasks. The poor readers' specific difficulty with phonetically recodable stimuli, their reduced sensitivity to rhyme, and their tendency to produce a greater frequency of phonetic errors of transposition all support this conclusion. In this study, our concern is with the question of how to characterize this deficit: Do poor readers create/maintain a deviant phonetic code, or is their use of phonetic coding ineffective for some other reason? Most of the studies of the short-term memory performance of good and poor readers have assessed performance by calculating the number of items correctly reported. However, analyzing the nature of errors, rather than simply the incidence of errors, can offer a way of determining how good and poor readers actually function in STM tasks. Our first effort in this direction offered some interesting results in terms of the occurrence of phonetic transposition errors (Brady et al., 1983). Since phonetic transposition errors were made by both good and poor readers, it would seem that both groups employ some type of phonetic code. Yet the higher occurrence of these errors for poor readers suggests some reading group differences in phonetic processing skills that remain to be explained.

One limitation of our earlier study was that it employed materials that had not been designed to allow the rigorous analysis of memory errors carried out in recent studies of STM in adults (see Drewnowski, 1980; Ellis, 1980). Thus we could not probe the role of such factors as the 
phonetic feature composition and adjacency of neighboring stimuli on the incidence of errors by good and poor readers. These factors influence the pattern of transposition errors made by adult subjects, and we might presume that they influence the behavior of young good readers given that these readers show an adult-like susceptibility to other manipulations of phonetic factors. Our present question is whether phonetic feature similarity and adjacency of stimuli would influence the error pattern of good and poor readers to the same extent. If so, it would provide evidence of similar phonetic coding strategies on the part of both groups of children and would imply that the difficulties of the poor readers lie instead in either the creation, maintenance, or retrieval of that code. However, should the pattern of the poor readers' errors prove truly discrepant with regard to the influence of feature similarity and item adjacency, it would imply use of a deviant code as a source of their STM problems.

To answer this question, two experiments were conducted to examine the role of phonetic factors and adjacency on STM performance by good readers and poor readers. Given our previous finding that poor readers make more phonetic transposition errors than do good readers, our aim was to replicate that finding, and to examine the phonetic coding factors involved. In each experiment the subjects' task was to repeat lists of spoken nonsense syllables in which we had manipulated the phonetic similarity of the initial consonants, following the methods employed for studying these factors with adult subjects (Ellis, 1980). Nonsense syllables were used because they allow for systematic variation of the phonetic properties of the materials and they avoid familiarity effects on recall. In keeping with Ellis's design, we constructed lists of nonsense syllables such that items in the strings shared zero, one, or two features of the initial consonant. Across lists of syllables, the order of the stimuli also varied systematically as a probe to the questions of whether adjacent items were more likely to be transposed than were nonadjacent ones, and whether the number of shared features interacts with any influence of adjacency. This orthogonal manipulation of shared features and adjacency ultimately permitted us to determine the effects of the phonetic structure of the materials on the pattern of errors. Analysis of such effects as they relate to reading ability and the accuracy of recall can provide information on the use of phonetic coding by good and poor readers.

\section{EXPERIMENT 1}

In the first experiment good and poor readers were given lists of the syllables $/ \mathrm{s} 2 /, / \mathrm{za} /, / \mathrm{g} \partial /$, and $/ \mathrm{ka} /$ for recall. Using a conventional phonetic feature analysis, the consonants in these stimuli can be compared on voicing, place of articulation, and manner. Pairs of the syllables share zero, one, or two phonetic features, allowing an analysis of transposition errors in terms of phonetic feature similarity. In addition, the position of each syllable in the string was systematically varied to permit an evaluation of the effects of position on error rate. Based on previous work we expected good readers' errors to reflect the use of a phonetic coding strategy; hence, we expected their incidence of transposition errors to be a function of phonetic feature similarity. Our primary goal was to determine whether poor readers' errors would also reveal the effects of phonetic processing.

\section{Method}

Subjects. In Experiment 1, the subjects were second-grade children from two elementary schools in a suburban school district in Rhode Island. A school reading specialist, a principal, and the classroom teachers helped to preselect the poorest readers and the best readers from the second-grade classes. In a supplementary screening procedure, the Word Attack and Word Recognition subtests of the Woodcock Reading Mastery Tests, Form A (Woodcock, 1973), and a test of receptive vocabulary, the Peabody Picture Vocabulary Test-Revised (PPVT-R; Dunn 1981), were administered to the children.

A student's inclusion in the study was determined by the following criteria: (1) To ensure valid classification as a good or poor reader, the scores on the two Woodcock subtests had to be consistent. (2) In order to restrict the range of IQ scores, only subjects with scores from 90 to 135 on the PPVT were eligible for further testing. (3) Given the evidence that STM span increases with age (see Dempster, 1981), subjects were selected whose ages fell within the limited range of 88-100 months.

Twenty-eight children satisfied the requirements for participation in the study. Based on the scores that were obtained on the reading tests, two groups were formed that were nonoverlapping in reading level. The 14 children who qualified as good readers were well beyond the end of second-grade reading performance (testing was done in the spring), with a mean reading grade level of 5.0. The 14 children labeled poor readers had an average reading grade level of 2.1 and lagged considerably behind their peers. The IQ scores, as determined by the PPVT, did not differ significantly $[F(1,26)=.66, M S e=90.4, p=.423]$. The mean IQ score for the good readers was 114 , and for the poor readers 111 . The reading groups also did not significantly differ in age $[F(1,26)=.05$, $M S e=18.6, p=.828$ ]. The good readers had a mean age of 96.1 months, and the poor readers had a mean age of 96.4 months.

Materials and Procedure. The materials comprised lists of four nonsense syllables presented auditorily in 3 practice trials and 12 test sequences. In all sequences the stimuli were the consonantvowel (CV) syllables $/ \mathrm{s} 2 /, / \mathrm{zo} /, / \mathrm{g} /$, and $/ \mathrm{kJ} /$. In these syllables, the vowel is held constant, and the initial consonants share zero, one, or two phonetic features. The four syllables can be combined into 6 possible pairs, two that share no features, two that share one feature, and two that share two features (as detailed in Table 1). The trials consisted of randomizations of these four syllables in which each consonant occurred only once per list and three times at each of the serial positions 1 to 4 . For the six stimulus pairs, each occurred twice (once in each order, e.g., /so/, /zo/, and /zo/, $/ \mathrm{s} / /$ ) at each of the serial positions 1 and 2,2 and 3 , and 3 and 4 .

The practice trials and test sequences were read with a neutral intonation by a phonetically trained male speaker and were recorded on magnetic tape. The materials were presented to subjects through headphones. Within each list, the syllables were spoken with a neutral prosody at the rate of one per second. The subjects' responses were recorded in case of experimenter difficulty in documenting responses. Subsequent comparisons of the written and audio versions confirmed the accuracy of the transcribed responses.

Each child was tested individually for two sessions in a small room provided by the school. The first session consisted of the 
Table 1

Experiment 1: The Consonant Pairs Described in Terms of Shared Phonetic Features

\begin{tabular}{ccccc}
\hline & \multicolumn{3}{c}{ Phonetic Feature* } & \\
\cline { 2 - 4 } $\begin{array}{c}\text { Consonant } \\
\text { Pairs }\end{array}$ & Voicing & Place & Manner & $\begin{array}{c}\text { Number of } \\
\text { Shared Features }\end{array}$ \\
\cline { 2 - 5 } sz & - & + & + & 2 \\
gk & - & + & + & 2 \\
sk & + & - & - & 1 \\
zg & + & - & - & 1 \\
sg & - & - & - & 0 \\
zk & - & - & - & 0 \\
\hline
\end{tabular}

*A + sign indicates that the two consonants have the same categorization for the listed feature.

screening procedure, the second the memory task. In the second session the practice trials were presented (repeated if necessary), followed by the test sequences. For each trial, subjects were in structed to repeat the items in the order they had been presented, as soon as the list ended.

\section{Results and Discussion}

In a preliminary analysis of the data, the number of correct responses was tabulated in terms of item order and serial position, as is customarily done in studies of shortterm recall in good and poor readers. The innovation was to further analyze the errors qualitatively, focusing on the instance of transpositions in relation to whether the transposed syllable was adjacent to the target syllable in the test sequence, and in relation to the phonetic feature similarity between target syllable and the transposed response. The statistical analyses for all scoring procedures were based on the raw scores for each subject. For ease of comparison between reading groups and with other published research, the data were converted to percentage values in the tables.

Analysis of correct responses. Since the same items were presented on each trial, varying only in terms of order, an order-correct scoring procedure was adopted. A response was considered correct only if it had been assigned to the appropriate serial position. Table 2 shows the mean percentage of correctly reported items at each serial position for each group of subjects. Consistent with earlier studies, the good readers were notably more accurate overall than were the poor readers $[F(1,26)=9.91$, $M S \mathrm{e}=4.8, p=.004]$. There was a significant effect of serial position $[F(3,78)=36.46, M S e=1.0, p<.001]$, with no interaction of serial position and reading group $[F(3,78)=1.52, M S \mathrm{e}=1.0, p=.216]$.

Analyses of covariance (ANCOVAs), using IQ and age as the covariates, were conducted to evaluate whether the obtained differences in performance might be attributed to differences in age or in intelligence between good and poor readers in our sample. Neither analysis altered the pattern of results ${ }^{1}$ : the good readers were still superior in recall with IQ as the covariate $[F(1,25)=8.72, M S e=$ $4.8, p=.007]$, and with age as the covariate $[F(1,25)$ $=9.47, M S \mathrm{e}=5.0, p=.005]$.

Thus, it is clear that the characteristic differences in STM recall between good and poor readers were obtained with the present task. Having replicated this pattern, we turned our attention to the nature of the errors for both reading groups.

Error analysis. The errors were first categorized as misplacements of phonetic information that had been in the string, errors of omission (no response), or substitution errors (the intrusion of phonemes that were not in the original list). (A negligible number of omission errors occurred, so these responses were grouped with the substitution errors for statistical purposes.) The majority of errors fell within the first category, phonemes that had occurred elsewhere in the string $[F(1,26)=56.04, M S e$ $=10.4, p<.001]$, and this was true for both good readers $($ mean $=74 \%)$ and poor readers (mean $=73 \%$ ). Since the vowel was the same for all items, it is not possible to determine whether these order errors were phoneme transpositions or entire syllable order errors.

The construction of the present experiment, using phonemes that differ systematically in shared features, allows us to examine the conditions under which these order errors occurred. Two parameters were measured. First, an error was evaluated as having been, in the original string, adjacent to the target or nonadjacent (e.g., in target string "gə, zə, kə, sə" and reported string "gə, sə, $k \partial$, z $ə$ ", the original locations of the reversed items were nonadjacent). Second, an error was scored in terms of the number of features shared between the substitute response and the target item (e.g., in a reversal of $/ g /$ and target $/ \mathrm{k} /$, there are two features in common).

As shown in Table 3, the source (i.e., original location) of substituted stimuli was a significant factor for both good and poor readers. Errors were significantly more

Table 2

Experiment 1: The Mean Percentage of Items Correctly Reported, Listed by Serial Position

\begin{tabular}{lcccc}
\hline & \multicolumn{4}{c}{ Serial Position } \\
\cline { 2 - 5 } & 1 & 2 & 3 & 4 \\
\hline Good Readers & 72 & 50 & 38 & 38 \\
Poor Readers & 50 & 35 & 23 & 30 \\
\hline
\end{tabular}

Table 3

Experiment 1: Adjacency* and Feature Similarity $\dagger$ Effects in Phoneme Order Errors

\begin{tabular}{|c|c|c|c|c|}
\hline & \multicolumn{3}{|c|}{ Shared Features } & \multirow[b]{2}{*}{ Total } \\
\hline & 0 & 1 & 2 & \\
\hline \multicolumn{5}{|c|}{ Good Readers } \\
\hline Adjacent & 16 & 25 & 21 & 62 \\
\hline Nonadjacent & 8 & 12 & 17 & 37 \\
\hline Total & 24 & 37 & 38 & \\
\hline \multicolumn{5}{|c|}{ Poor Readers } \\
\hline Adjacent & 17 & 16 & 21 & 54 \\
\hline Nonadjacent & 11 & 12 & 22 & 46 \\
\hline Total & 28 & 28 & 43 & \\
\hline
\end{tabular}

*The mean percentage of times the error consisted of an item from an adjacent or nonadjacent position. †The mean percentage of errors for each number of shared features between reported item and target. 
likely to involve a syllable adjacent to the target than a nonadjacent syllable $[F(1,26)=11.44, M S e=4.2, p=$ $.002]$, but there was no interaction between this effect and reading group $[F(1,26)=1.63, M S e=4.2, p=.213]$. This suggests that the subjects had retained some information about the relative position of items in the original string even when they were unable to make a fully accurate report.

The second qualitative scoring procedure, which evaluated the phonetic similarity between errors and target stimuli, is more central to our interest in the coding skills of good and poor readers. Would the incidence of order errors be greater for stimuli that shared two features than for those with one or none in common (see Table 3)? A significant effect of phonetic similarity was obtained $[F(2,52)=7.93, M S e=3.6, p<.001]$, underscoring the phonetic basis for storage in STM. Yet the effect did not significantly differ for good and poor readers $[F(2,52)$ $=2.66, M S \mathrm{e}=3.6, p=.079$ ], suggesting that both reading groups were relying on phonetic representation.

The effects of feature similarity on the occurrence of errors were also analyzed for the order errors involving adjacent and nonadjacent target stimuli. The interaction of adjacency and similarity on the incidence of errors was nonsignificant $[F(2,52)=2.72, M S e=3.6, p=.075]$. Likewise, no significant interaction was obtained between reading group, similarity, and adjacency $[F(2,52)=.60$, $M S e=3.6, p=.553]$.

In sum, in this experiment poor readers were found to recall significantly less information than did good readers. However, like good readers' errors, the errors of poor readers consisted largely of information that had been in the original string but reported in the wrong order, rather than errors of omission or substitution. Further analyses showed that these order errors revealed significant effects of adjacency and of phonetic similarity. Thus the errors of poor readers show the same systematic effects of processing as do the errors of good readers, but they occur at a higher rate. The implication would seem to be that poor readers employ the same coding strategy as do good readers, but less effectively, leading them to make more errors, but not different types of errors, than do good readers.

\section{EXPERIMENT 2}

To determine the generality of the results to other consonants and other classes of phonemes, we next tested good and poor readers on a second set of items consisting of syllables that started with the consonants $/ \mathrm{m} /, \mathrm{n} /$, $/ \mathrm{b} /$, and $/ \mathrm{k} /$, using the same procedure as in Experiment 1 . In addition to a same-vowel condition, Experiment 2 also employed a mixed-vowel condition to further explore the nature of order errors. In the mixed-vowel condition, it is possible to analyze whether order errors consist of transpositions of phonetic segments (e.g., $/ \mathrm{mI} /, / \mathrm{næ} /$ for $/ \mathrm{nI} /$, $/ \mathrm{mæ} /$ ) or of syllable misorderings (e.g., /mæ/, $/ \mathrm{n} /$ for
$/ \mathrm{n} /, / \mathrm{mæ} /$. In this way we hoped to make a more finegrained analysis of the coding strategies of good and poor readers.

\section{Method}

Subjects. The same subjects were recruited for participation in Experiment 2, conducted in the spring of the following school year (third grade). Four children were no longer available, 2 good readers and 2 poor readers. The remaining children were reevaluated for inclusion in the study, in accord with the criteria outlined for Experiment $1 .^{2}$ For all subjects, placement in a reading group was the same as it had been the previous year. Additional children were screened to increase the number of subjects in each group. Two children qualified as good readers and 4 as poor readers, bringing the group sizes to 14 good readers and 16 poor readers.

As before, the reading groups were nonoverlapping in reading level. The 14 good readers had a mean reading grade level of 8.7 , whereas the 16 children who were labeled poor readers had a mean reading grade level of 2.9. The PPVT IQ scores did not differ significantly for the reading groups [good readers, mean $=113$; poor readers, mean $=111 ; F(1,28)=.52, M S e=87.6, p=.476]$. Nor did the ages significantly differ [good readers, mean = 107.2 months; poor readers, mean $=108.3$ months; $F(1,28)=.45$, $M S \mathrm{e}=18, p=.509]$.

Materials and Procedure. Experiment 2 was designed to be parallel to Experiment 1 but with different stimulus sets. As in Experiment 1 , a trial consisted of four nonsense syllables presented auditorily, and the subjects were asked to repeat the list in the order of presentation. There were now two conditions, a same-vowel condition and a mixed-vowel condition. The construction of the test sequences was identical to that of Experiment 1. The initial consonants of the test items in each set again had zero, one, or two phonetic features in common with the other stimuli selected (see Table 4). In the same-vowel condition the stimuli were $/ \mathrm{ma} /, / \mathrm{na} /$, $/ \mathrm{b} /$, and $/ \mathrm{k} /$. In the nonrhyme set, the consonants were randomly paired with the vowels $/ \mathrm{I} /, / \mathrm{e} /, / \mathrm{o} /, / \mathrm{\partial} /, / \mathrm{a} /, / \mathrm{JI} /, / \mathrm{II} /, / \mathrm{el} /, / \mathfrak{a} /$, and $/ u /$ (with the stipulation that $C V$ combinations sounding like real words were excluded).

The preparation of stimulus tapes and the method of testing also mirrored the procedures adopted in Experiment 1, except that each child was tested in three sessions (one screening session and two memory-task sessions). In each memory-task session, a subject had three practice trials (repeated if necessary) and six test trials for one condition (e.g., same-vowel), followed by three (or more) practice trials and six test trials for the other condition (e.g., mixedvowel). The order of test conditions was reversed for the second session. Within each reading group, half of the subjects began with the same-vowel condition, half with the mixed-vowel condition.

Table 4

Experiment 2: The Consonant Pairs Described in Terms of Shared Phonetic Features

\begin{tabular}{ccccc} 
& \multicolumn{3}{c}{ Shared Phonetic Features } \\
\cline { 2 - 4 } $\begin{array}{c}\text { Consonant } \\
\text { Pairs }\end{array}$ & Voicing & Place & Manner & $\begin{array}{c}\text { Number of } \\
\text { Shared Features }\end{array}$ \\
\cline { 2 - 5 } mn & + & - & + & 2 \\
mb & + & + & - & 2 \\
nb & + & - & - & 1 \\
bk & - & - & + & 1 \\
mk & - & - & - & 0 \\
nk & - & - & - & 0 \\
\hline
\end{tabular}

*A + sign indicates that the two consonants have the same categorization for the listed feature. 
Table 5

Experiment 2: The Mean Percentage of Consonants Correctly Reported, Listed by Serial Position

\begin{tabular}{lcccc}
\hline & \multicolumn{4}{c}{ Serial Position } \\
\cline { 3 - 5 } & 1 & 2 & 3 & 4 \\
\hline Good Readers & & & & \\
Same-Vowel Set & 83 & 67 & 59 & 65 \\
Mixed-Vowel Set & 74 & 57 & 61 & 67 \\
Poor Readers & & & & \\
Same-Vowel Set & 67 & 55 & 42 & 47 \\
Mixed-Vowel Set & 69 & 52 & 44 & 52 \\
\hline
\end{tabular}

\section{Results and Discussion}

The results will be described jointly for the two vowel conditions, scored and presented as in Experiment 1. First, the correct response data will be discussed, followed by the error analysis results.

Analysis of correct responses. In Table 5 the mean percentage correct at each serial position is listed for the two vowel conditions, same-vowel and mixed-vowel. For these values, the data have been analyzed only for consonant information. Thus, in this analysis the vowel responses were not scored. Except for recall being a little better for all subjects, as expected for older children, the results replicate those in Experiment 1. Good readers were superior to poor readers in recall in both the samevowel condition $[F(1,28)=14.25, \mathrm{MSe}=6.3, p<.001]$ and the mixed-vowel condition $[F(1,28)=5.64, M S e=$ $6.7, p=.025]$. In addition, the serial position effect was significant for both vowel conditions [same-vowel, $F(3,84)=21.21, M S \mathrm{e}=1.1, p<.001 ;$ mixed-vowel, $F(3,84)=17.96, M \mathrm{Se}=1.1, p<.001]$. However, there was no interaction between serial position and reading group [same-vowel, $F(3,84)=1.36, M S \mathrm{e}=1.1, p=$ .261 ; mixed-vowel, $F(3,84)=.47, M S \mathrm{e}=1.1, p=$ .704].

Interestingly, recall of consonants appears to be independent of the vowel environment. There was a striking lack of difference in error rate for consonants for the two vowel sets $[F(1,28)<1.00]$. That this held for both reading groups is supported by the lack of a group $\times$ vowel set interaction $[F(1,28)=2.43, M S \mathrm{e}=2.3, p=.130]$.

In most memory studies, the consonants are not scored in isolation, but rather the entire response is scored as correct or not. We will now present the data in this fashion, counting a response as correct only if both the consonant and vowel were accurately reported. Scoring the entire syllable, a substantial difference in accuracy is now present for the two sets $[F(1,28)=146.49, M S e=$ $1.5, p<.001]$. This can be seen in Table 6 . Of course, the error rate for the same-vowel set is the same as plotted for the consonant scoring, since subjects do not make mistakes on the vowels in this task. This is not so for the mixed-vowel set, where the amount of information to be recalled is much greater. Subjects must retain both the consonant and the vowel, and with nonsense syllables this cannot be facilitated by semantic information. The in- creased memory load is reflected in the lower accuracy for the mixed-vowel condition.

With regard to the influence of the two vowel sets on good versus poor readers, good readers showed greater improvement on the easier items (same-vowel set) than did the poor readers. This is reflected in the significant interaction of vowel set and reading group $[F(1,28)=$ $8.59, M S \mathrm{e}=1.5, p=.007]$. The particular pattern of errors by good and poor readers for vowels and consonants will be discussed below in the Error Analysis section. The results of the same-vowel and mixed-vowel conditions in relation to results of other studies investigating the effects of rhyme on recall will be addressed in the conclusion.

In sum, the results of the correct response analyses show that good readers performed significantly better on both conditions (same- and mixed-vowel) and for both scoring techniques (consonant alone and whole syllable).

Error analysis. We found, as in Experiment 1, that the majority of consonant errors consisted of misorderings of the items in the string, rather than substitutions of new items or omissions. This effect was significant for both the same-vowel condition [good readers, mean $=90 \%$; poor readers, mean $=88 \% ; F(1,28)=135.11, M S \mathrm{e}=$ $2.0 ; p<.001]$ and the mixed-vowel condition [good readers, mean $=89 \%$; poor readers, mean $=93 \%$; $F(1,28)=196.08$, MSe $=3.2 ; p<.001]$.

However, in the mixed-vowel set, in which we can examine vowel errors, the errors for consonants and vowels differed somewhat. As noted, the reading groups differed significantly on the consonant errors $[F(1,28)=5.64$, $M S \mathrm{e}=6.7, p=.025 \mathrm{~J}$, but the difference was not obtained for vowel errors $[F(1,28)=2.51, M S e=21.1$, $p=.124]$. Although both groups produced many errors on the vowels, error rate did not distinguish the groups.

Table 7 displays the ways in which the consonants and vowels vary as to error type. First, as stated earlier, for the consonants, very few errors consisted of substitutions or omissions. With such a limited data set, this is as expected. In contrast, for the vowels, a larger set of stimuli was possible in any particular string, and a fair number of substitution errors occurred. Second, few of the errors for either reading group consisted of entire syllable misorderings, and no group difference was observed for this error type $[F(1,28)=1.90, M S e=7.3, p=.179]$. Third, the majority of errors consisted of transpositions

Table 6

Experiment 2: The Mean Percentage of Syllables Correctly Reported, Listed by Serial Position

\begin{tabular}{lllll}
\hline & \multicolumn{4}{c}{ Serial Position } \\
\cline { 2 - 3 } & 1 & 2 & 3 & 4 \\
\hline Good Readers & & & & \\
Same-Vowel Set & 83 & 67 & 59 & 65 \\
Mixed-Vowel Set & 54 & 36 & 33 & 45 \\
Poor Readers & & & & \\
Same-Vowel Set & 67 & 55 & 42 & 47 \\
Mixed-Vowel Set & 43 & 31 & 21 & 34 \\
\hline
\end{tabular}


Table 7

Experiment 2: Mixed-Vowel Condition, Analysis of Errors

\begin{tabular}{|c|c|c|c|c|}
\hline \multirow[b]{2}{*}{$\begin{array}{l}\text { Reading } \\
\text { Group }\end{array}$} & \multirow[b]{2}{*}{$\begin{array}{c}\text { Mean \% } \\
\text { Errors }\end{array}$} & \multicolumn{3}{|c|}{ Analysis of Errors (\%) } \\
\hline & & $\begin{array}{l}\text { Syllable } \\
\text { Order* }\end{array}$ & Transposition $\dagger$ & $\begin{array}{c}\text { Omission } \ddagger \\
+ \text { Substitution§ } \\
\end{array}$ \\
\hline \multicolumn{5}{|c|}{ Consonant Errors } \\
\hline $\begin{array}{l}\text { Good } \\
\text { Poor }\end{array}$ & $\begin{array}{l}35 \\
46\end{array}$ & $\begin{array}{l}12.2 \\
15.6\end{array}$ & $\begin{array}{l}77.2 \\
77.6\end{array}$ & $\begin{array}{r}10.6 \\
6.8\end{array}$ \\
\hline \multicolumn{5}{|c|}{ Vowel Errors } \\
\hline $\begin{array}{l}\text { Good } \\
\text { Poor }\end{array}$ & $\begin{array}{l}32 \\
39\end{array}$ & $\begin{array}{l}13.5 \\
18.0\end{array}$ & $\begin{array}{l}39 \\
44.4\end{array}$ & $\begin{array}{l}47.5 \\
37.6\end{array}$ \\
\hline
\end{tabular}

*Whole syllable in wrong position. tConsonant transposition: consonant in wrong position with new vowel. Vowel transposition: vowel in wrong position with new consonant. ‡No response. §Response given that was not in original string.

of the available consonants and vowels, which create new syllables.

Let us next look, as in Experiment 1, at the effects of adjacency and phonological similarity on the occurrence of consonant errors. It is clear from Table 8 that there is a pronounced effect of adjacency on errors in both vowel conditions. For both good and poor readers, transpositions more often involved consonants from adjacent than from nonadjacent syllables [same-vowel set, $F(1,28)$ $=104.72, M S e=3.2, p<.001$; mixed-vowel set, $F(1,28)=41.71, M S e=4.6, p<.001]$. The similarity of these effects for good and poor readers is confirmed by the lack of an interaction between reading group and the effect of adjacency [same-vowel set $F(1,28)=3.8$, $M S e=3.2, p=.544 ;$ mixed-vowel set, $F(1,28)=.01$, $M S \mathrm{e}=4.6, p=.908]$. Furthermore, there were also significant effects of phonetic feature similarity on the incidence of transposition errors [same-vowel set, $F(2,56)=$

Table 8

Experiment 2: Adjacency* and Feature Similarity $\dagger$ Effects in Order Errors

\begin{tabular}{|c|c|c|c|c|c|}
\hline & & \multicolumn{3}{|c|}{ Shared Features } & \multirow[b]{2}{*}{ Total } \\
\hline & & 0 & 1 & 2 & \\
\hline \multicolumn{6}{|c|}{ Same-Vowel Set } \\
\hline \multirow[t]{3}{*}{ Good Readers } & Adjacent & 19.6 & 28.1 & 30.7 & 78.4 \\
\hline & Nonadjacent & 4.7 & 5.9 & 11.1 & 21.7 \\
\hline & Total & 24.3 & 34 & 41.8 & \\
\hline \multirow[t]{3}{*}{ Poor Readers } & Adjacent & 21.9 & 24.1 & 25.3 & 71.3 \\
\hline & Nonadjacent & 5.2 & 8.9 & 14.5 & 28.6 \\
\hline & Total & 27.1 & 33 & 39.8 & \\
\hline \multicolumn{6}{|c|}{ Mixed-Vowel Set } \\
\hline \multirow{3}{*}{ Good Readers } & Adjacent & 27.7 & 20.7 & 28.3 & 70.7 \\
\hline & Nonadjacent & 7.1 & 7.5 & 14.6 & 29.2 \\
\hline & Total & 28.8 & 28.2 & 42.9 & \\
\hline \multirow[t]{3}{*}{ Poor Readers } & Adjacent & 17.5 & 24.6 & 22.8 & 64.9 \\
\hline & Nonadjacent & 8.0 & 9.5 & 17.5 & 35 \\
\hline & Total & 25.5 & 34.1 & 40.3 & \\
\hline
\end{tabular}

*The mean percentage of times the error consisted of an item from an adjacent or nonadjacent position. †The mean percentage of errors for each number of shared features between reported item and target.
$6.51, M S \mathrm{e}=3.5, p=.003 ;$ mixed-vowel set, $F(2,56)$ $=5.96, M S \mathrm{e}=4.4, p=.005]$, with no interaction between reading group and the effect of feature similarity [same-vowel set, $F(2,56)=.03, M S \mathrm{e}=3.5, p=.975$; mixed-vowel set, $F(2,56)=.71, M S \mathrm{e}=4.4, p=.497]$. Order errors were thus more likely to occur between stimuli that shared phonetic information.

As in Experiment 1, there was not a significant interaction between the effects of adjacency and phonetic similarity [same-vowel condition, $F(2,56)=.58, M S e=$ $2.6, p=.637$; mixed-vowel condition, $F(2,56)=1.83$, $M S \mathrm{e}=2.2, p=.170]$. Nor were significant interactions obtained between reading group, adjacency, and similarity [same-vowel condition, $F(2,56)=1.28, M S \mathrm{e}=2.6$, $p=.285$; mixed-vowel condition, $F(2,56)=1.88, M S \mathrm{e}$ $=2.2, p=.161]$.

To summarize, although the poor readers made more errors than did good readers on both consonant and vowel information, it was only consonant accuracy on which the groups significantly differed. Of the consonant errors, the majority for both good and poor readers consisted of reorderings of the phonetic information in the string. These recombinations showed strong influences of adjacency and phonetic similarity reflecting, we presume, the underlying processing strategies. The kinds of errors suggest that the inferior performance of poor readers on these short-term memory tasks is not the consequence of a different coding strategy, but rather of a lesser degree of skill with a phonetic strategy.

\section{CONCLUSION}

Our goal was to conduct studies that would allow us to determine the coding processes of good readers and poor readers on short-term memory tasks. Previous work (Brady et al., 1983) had provided preliminary evidence that poor readers, like good readers, may use a phonetic code in STM. In the present experiments this question was directly evaluated using nonsense strings in which the phonetic similarity of the items was controlled. Use of nonsense materials limits the types of coding strategies, and allows us to probe whether the phonetic coding strategies of the poor readers are affected by the same factors as are those of the good readers.

Good and poor readers in the second grade (Experiment 1) and third grade (Experiment 2) were tested on recall tasks with differing sets of consonant-vowel syllables. The results of the two experiments are congruent: First, consistent with previous research, poor readers made more errors than did good readers, underscoring the fact that their problem extends beyond recall of printed material to recall of spoken material. Second, looking more closely at the pattern of errors made by poor readers, it was observed that their significantly higher error rate reflected poor memory of consonant information. Although both good and poor readers produced a fair number of errors for vowels, the error rate did not distinguish reading groups. Third, as might be expected given the limited number of items in our corpus (particularly 
in Experiment 1), most errors involving consonants were errors of item order rather than errors of item identity (Healy, 1974), and this was the case for good and poor readers alike. In general, the order confusions were more likely to occur between adjacent items than between nonadjacent items, and this was equally true for both good and poor readers. More importantly, the pattern of consonant errors for both reading groups revealed significant effects of phonetic similarity between the two items that were transposed. In sum, then, consonant transposition errors were significantly more frequent for the children with reading problems. Poor readers, however, did not differ from good readers in the composition of their errors, and both groups were influenced by the adjacency and phonetic similarity of items in the string being recalled.

The factors of phonetic similarity and adjacency have been noted as important aspects of STM processing for adults (Drewnowski \& Murdock, 1980; Ellis, 1980). Several authors have noted that errors in recall by adults show effects of feature similarity (Cole, Haber, \& Sales, 1968; Cole, Sales, \& Haber, 1969; Hintzman, 1967; Wickelgren, 1966). Furthermore, Ellis (1980) documented effects of phonetic parameters on the occurrence of transposition errors by adults on tasks that are similar to those in the present experiments. Hitch (1974) and Ryan (1969) also reported a strong effect of adjacency in the recall errors of adults that is like the effect seen in our study. These findings and those of the present study need to be incorporated into models of short-term memory. For example, the prevalence of transposition errors, in which consonant and vowel elements recombine to form new items, indicates that the syllable may not be the storage unit in STM. Apparently smaller phonetic units become relevant in the storage process. Current models that detail the incidence of item and order errors (e.g., Lee \& Estes, 1981) could be extended to incorporate the role of phoneme or feature-size units in conceptions of information storage. Our intent in this study is not to develop such a model; our interest lies in the finding that the same processing strategies appear to be at work for adults, children who are good readers, and children who are poor readers.

In previous studies efforts to discern the coding strategies of poor readers have tended to focus on the effects of rhyme on recall performance. As mentioned in the introduction, adult subjects and good readers usually have better recall for lists of nonrhyming items than for lists of rhyming stimuli (e.g., Baddeley, 1966; Shankweiler et al., 1979). The greater confusion in recall when the items are phonetically similar has been taken as reflecting in the use of phonetic coding processes in STM. In earlier studies good readers have been penalized by manipulations of rhyme to a greater extent than have poor readers, leading to the conclusion that poor readers make less effective use of phonetic representation (Mann et al., 1980; Shankweiler et al., 1979). However, these findings have been obtained for longer sequences than those used in the present experiments. In the present study, sequences were deliberately kept short so as to optimize the subject's ability to recall the correct number of stimuli, and thereby facilitate the examination of order errors (i.e., syllable misorderings) and transposition errors (i.e., transpositions of phonetic elements) in the reported items. In these circumstances we found no penal effect of rhyme; consonants were recalled no better in the mixed-vowel set than in the same-vowel set. Thus, effects of rhyme may well depend on how taxed the system is (a similar idea has been expressed by Hall, Wilson, Humphreys, Tinzmann, \& Bowyer, 1983). The everyday experience that rhyme facilitates recall may be related to this.

That rhyme effects are tied to task factors has also been suggested by results obtained for adults (see Watkins, Watkins, \& Crowder, 1974). In a paradigm similar to the present one, Ellis (1980), using short strings of nonsense syllables, did not find significant differences in the error rates for an all-same vowel condition and for an alldifferent vowel condition (although with other conditions there was a significant effect of vowel environment on error rate). Thus, we are not alone in finding that the particular type of STM task used in the present experiment does not produce the standard rhyme effect. As found for adults, task factors also appear to influence the relative difficulty of rhyming strings for younger good and poor readers. Hanson, Liberman, and Shankweiler (1984) found repeated rhyming strings to be easier for subjects in a study employing short sequences (four items) with the same stimuli repeated on each trial in varying order. In addition, the "rhyme effect" appears to be sensitive to subject characteristics (Hall et al., 1983) and to age effects (Olson et al., 1984). It is evident that additional work is necessary to understand the basis of the traditional rhyme effect in STM. However, although the effects of rhyme have proved to be somewhat labile, it is important to keep in mind that previous STM studies with children varying in reading ability show that the levels of recall on STM tasks have consistently distinguished reading groups. It is that difference that we seek to explain.

A finding by Case, Kurland, and Goldberg (1982) offers an account of why children, in general, perform less well than older individuals, and may also apply to poor readers. These authors argue that as a child matures, basic encoding and retrieval operations in STM become more efficient, resulting in more functional storage space (and in a concomitant increase in short-term memory capacity). In support of this interpretation, they report a linear relationship between increases in memory span and increases in speed of word repetition for normal children 3-6 years of age. Their position is buttressed by an additional experiment in which adults were forced to count in an unfamiliar language: The speed of counting for the adults was equal to the rate of 6-year-old children, and their memory span correspondingly dropped. It may be worth noting that individual differences in memory span are found throughout the lifespan. Furthermore, there is another indication that phonological skills also vary for adults and that these two findings may be related: Baddeley, Thomson, and Buchanan (1975) found that adults' 
memory span could be predicted on the basis of the number of words that the subject could read in approximately $2 \mathrm{sec}$.

Based on the findings by Case and Baddeley and their colleagues, we suggest that good and poor readers' differences in STM relate to a difference in the efficiency with which they process phonetic information. The present work indicates that children who are poor readers use the same phonetic processes in STM as do good readers or adults, but are less proficient. It is of course possible that effects of feature similarity on auditory memory tasks may be related to perception or production factors entailed in these tasks. In a subsequent series of experiments, we have explored further the relationship of phonetic processing skills and short-term memory skills to determine whether that relationship may account for the developmental changes in short-term memory that have been observed, and for the memory differences for children differing in reading ability. We obtained significant correlations on a variety of phonological tasks between the efficiency of phonetic processes and verbal short-term memory span, both in a developmental study with 4-8 year olds and in an experiment with third-grade good and poor readers (Brady, 1986). These findings converge with the present results to indicate that poor readers have normal, though less automatic, phonetic coding.

\section{REFERENCES}

Alegria, J., \& Pignot, E. (1979). Genetic aspects of verbal mediation in memory. Child Development, 50, 235-238.

BADDELEY, A. D. (1966). Short-term memory for word sequences as a function of acoustic, semantic and formal similarity. Quarterly Journal of Experimental Psychology, 18, 362-365

Baddeley, A. D., Thomson, N., \& Buchanan, M. (1975). Word length and the structure of short-term memory. Journal of Verbal Learning \& Verbal Behavior, 14, 575-589.

Bauer, R. (1977). Memory processes in children with learning disabilities. Journal of Experimental Child Psychology, 24, 415-430.

BradY, S. (1986). Short-term memory, phonological processing and reading ability. Annals of Dyslexia, 36, 138-153.

Brady, S., Shankweiler, D., \& ManN, V. (1983). Speech perception and memory coding in relation to reading ability. Journal of Experimental Child Psychology, 35, 345-367.

Byrne, B., \& ShEA, P. (1979). Semantic and phonetic memory in beginning readers. Memory \& Cognition, 7, 333-338.

Case, R., Kurland, D. M., \& GoldberG, J. (1982). Operational efficiency and the growth of short-term memory span. Journal of Experimental Child Psychology, 33, 386-404.

Cole, R. A., Haber, R. N., \& Sales, B. D. (1968). Mechanisms of aural encoding: I. Distinctive feature for consonants. Perception \& Psychophysics, 3, 281-284.

Cole, R. A., Sales, B. D., \& Haber, R. N. (1969). Mechanisms of aural encoding: II. The role of distinctive features in articulation and rehearsal. Perception \& Psychophysics, 6, 343-348.

ConRaD, R. (1971). The chronology of the development of covert speech in children. Developmental Psychology, 5, 398-405.

Conrad, R. (1972). Speech and reading. In J. Kavanagh \& I. Mattingly (Eds.), Language by ear and by eye: The relationships between speech and reading. Cambridge, MA: MIT Press.

DEMPSTER, F. N. (1981). Memory span: Sources of individual and developmental differences. Psychological Bulletin, 89, 63-100.

DREWNOWSKI, A. (1980). Memory functions for vowels and consonants: A reinterpretation of acoustic similarity effects. Journal of Verbal Learning \& Verbal Behavior, 19, 176-193.
Drewnowski, A., \& Murdock, B. B. (1980). The role of auditory features in memory span for words. Journal of Experimental Psychology: Human Learning \& Memory, 6, 319-332.

Dunn, L. M. (1981). Peabody Picture Vocabulary Test-Revised. Circle Pines, MN: American Guidance Service.

ElLIs, A. W. (1980). Errors in speech and short-term memory: The effects of phonemic similarity and syllable position. Journal of Verbal Learning \& Verbal Behavior, 19, 624-634.

Hall, J. W., Wilson, K. P., Humphreys, M. S., Tinzmann, M. B., \& BowYer, P. M. (1983). Phonemic-similarity effects in good vs. poor readers. Memory \& Cognition, 51, 520-527.

Hanson, V. L., Liberman, I. Y., Shankweiler, D. (1984). Linguistic coding by deaf children in relation to beginning reading success. Journal of Experimental Child Psychology, 37, 378-393.

HEALY, A. F. (1974). Separating item from order information in shortterm memory. Journal of Verbal Learning \& Verbal Behavior, 13, 644-655.

Hintzman, D. L. (1967). Articulatory coding in short-term memory. Journal of Verbal Learning \& Verbal Behavior, 6, 312-316.

Hiтch, G. H. (1974). Short-term memory for spatial and temporal information. Quarterly Journal of Experimental Psychology, 26, 503-513.

Hogaboam, T., \& Perfetti, C. A. (1978). Reading skill and the role of verbal experience in decoding. Journal of Educational Psychology, 20, 717-729.

Holmes, D. R., \& MCKeEver, W. F. (1979). Material-specific serial memory deficit in adolescent dyslexics. Cortex, 15, 51-62.

JORM, A. R. (1983). The cognitive and neurological basis of developmental dyslexia: A theoretical framework and review. Cognition, 7 , 19-33.

KATZ, R. B. (1986). Phonological deficiencies in children with reading disability: Evidence from an object-naming task. Cognition, 22, 225-257.

Katz, R. B., Healy, A. F., \& Shankweiler, D. (1983). Phonetic coding and order memory in relation to reading proficiency: A comparison of short-term memory for temporal and spatial order information. Applied Psycholinguistics, 4, 229-250.

Katz, R. B., Shankweiler, D., \& Liberman, I. Y. (1981). Memory for item order and phonetic recoding in the beginning reader. Journal of Experimental Child Psychology, 32, 474-484.

LEE, C. L. \& ESTES, W. K. (1981). Item and order information in shortterm memory: Evidence for multi-level perturbation processes. Journal of Experimental Psychology: Human Leaming \& Memory, 7, 149-169.

Liberman, I. Y., Mann, V. A., Shankweiler, D., \& Werfelman, M. (1982). Children's memory for recurring linguistic and non-linguistic material in relation to reading ability. Cortex, 18, 367-375.

Liberman, I. Y., Shankweiler, D., Liberman, A. M., Fowler, C., \& FISCHER, F. W. (1977). Phonetic segmentation and recoding in the beginning reader. In A. S. Reber \& D. L. Scarborough (Eds.), Toward a psychology of reading: The proceedings of the CUNY Conferences (pp. 207-225). Hillsdale, NJ: Erlbaum.

Mann, V. A., Liberman, I. Y., \& Shankweiler, D. (1980). Children's memory for sentences and word strings in relation to reading ability. Memory \& Cognition, 8, 329-335.

ManN, V. A., Shankweiler, D., \& SMith, S. T. (1984). The association between comprehension of spoken sentences and early reading ability: The role of phonetic representation. Journal of Child Language, 11, 627-643.

Mark, L. S., Shankweiler, D., Liberman, I. Y., \& Fowler, C. A. (1977). Phonetic recoding and reading difficulty in beginning readers. Memory \& Cognition, 5, 623-629.

Olson, R. K., Davidson, B. J., Kliegl, R., \& Davies, S. E. (1984). Development of phonetic memory in disabled and normal readers. Journal of Experimental Child Psychology, 37, 187-206.

RYAN, J. (1969). Grouping and short-term memory: Different means and patterns of grouping. Quarterly Journal of Experimental Psychology, 21, 137-147.

Shankweiler, D., Liberman, I. Y., Mark, L. S., Fowler, C. A., \& FISCHER, F. W. (1979). The speech code and learning to read. Journal of Experimental Psychology: Human Leaming \& Memory, 5, 531-545. 
ToRGESEN, J. K. (1982). The study of short-term memory in learningdisabled children: Goals, methods and conclusions. In K. Gadov \& I. Bialov (Eds.), Advances in learning and behavioral disabilities (Vol. I). Greenwich, CT: JAI Press.

Vellutino, F., Pruzek, R., Steger, J., \& Meshoulam, U. (1973). Immediate visual recall in poor and normal readers as a function of orthographic-linguistic familiarity. Cortex, 8, 106-118.

Watkins, M. J., Watkins, O. C., \& Crowder, R. G. (1974). The modality effect in free and serial recall as a function of phonological similarity. Journal of Verbal Leaming \& Verbal Behavior, 13. $430-447$.

Wickelgren, W. A. (1966). Distinctive features and errors in shortterm memory for English consonants. Joumal of the Acoustical Society of America, 39, 388-398.

WINBURY, N. (1984). A developmental investigation of the use of phonetic and semantic memory codes in good and poor readers. Unpublished doctoral dissertation, University of Connecticut.
Woodcock, R. W. (1973). Woodcock Reading Mastery Tests. Circle Pines, MN: American Guidance Service.

\section{NO'TES}

1. In the remainder of the analyses for Experiments 1 and 2, the data were likewise reanalyzed controlling for age and IQ. In no case was the significance of the differences between reading groups reduced when age and IQ were controlled.

2. The criteria for inclusion were adjusted for children a year older. Subjects were selected whose ages fell within the range of $100-112$ months.

(Manuscript received June 13, 1985; revision accepted for publication November 24,1986 .) 